\title{
AS FOTOGRAFIAS HISTÓRICAS COMO DISPOSITIVOS DISCIPLINARES: O PODER SOBRE A FALA DO OUTRO EM UM CONTEXTO ESCOLAR
}

\author{
Eliza Bachega Casadel \\ Universidade Estadual Paulista Júlio de Mesquita Filho, \\ Bauru, São Paulo, Brasil
}

\begin{abstract}
Resumo: O presente artigo irá remeter às ideias de Michel Foucault, para analisar a apropriação das imagens históricas nos livros didáticos escolares. Em um primeiro momento, discutiremos quais são as condições de produção da própria imagem fotográfica, que, não raro, coaduna as estratégias do poder às estratégias do ver e do representar. Depois, remeteremos às condições de produção da reapropriação dessas imagens, produzidas quando elas são reinseridas em livros e em outros contextos discursivos. Nesse aspecto, as ideias de Foucault fornecem instrumentos pedagógicos que visam ampliar o domínio de conhecimentos dos alunos justamente ao problematizar a construção dos saberes constituídos.

Palavras-chave: Foucault. Fotografia. História. Poder. Estratégias discursivas.
\end{abstract}

A inserção de imagens em livros didáticos escolares participa de um processo que, se por um lado, é um indicativo da modernização do próprio suporte, ao trazer para a sala de aula linguagens diversificadas (e presentes na cotidianidade dos alunos), é também, por outro, um mecanismo útil de tradução didático-metodológica, que auxilia na elucidação de conceitos e teorias na relação ensino-aprendizagem (BELMIRO, 2000). O seu uso, contudo, levanta uma série de questões sobre a não-transparência dessas próprias imagens.

Énesse sentido que Silva et al (2006, p. 221) apontam para ofato de quea própria leitura das imagens precisa ser ensinada, uma vez que tal prática depende 
de condições sócio-históricas construídas. Segundo os autores, na decodificação das imagens, estão em jogo não apenas a materialidade da linguagem em questão, mas "também a posição do sujeito em uma dada formação discursiva", posto que "uma mesma imagem pode significar de diferentes modos". Eé por isso que "o sujeito não é o centro ou origem do processo de produção de sentidos, mas parte de um processo que se iniciou antes".

As imagens dos livros didáticos, portanto, delimitam certas partilhas entre os modos de ver e os modos de dizer, de forma que, tal como apontado por Faria $(1984$, p.6) corroboram modos de construção de mundo. A partir desses pressupostos, o presente artigo tem como objetivo discutir, a partir das ideias de Michel Foucault, o uso de fotografias históricas como instrumento educacional.

Em um primeiro momento, elucidaremos a forma como as fotografias se constituem como dispositivos disciplinares, a partir da relação estabelecida entre os modos de representar o mundo a partir das imagens fotográficas e os modos de poder. Nesse sentido, procuraremos mostrar que as fotografias históricas trazem sempre essa marca de inscrição, medição, registro e controle da realidade discursiva. Além disso, as fotografias não são produzidas de forma aleatória: há, por detrás de cada fotografia, certas condições discursivas que, a despeito das condições técnicas, permitem que algumas fotografias sejam produzidas e outras não. Após isso, também com base em Foucault, discutiremos a forma como o conhecimento histórico é sempre construído a partir de um discurso que fala, sobre o que o outro cala: as fotografias históricas usadas em sala de aula, nesse sentido, podem servir justamente como uma forma de elucidar esses mecanismos de poder junto aos alunos, de forma a problematizar as construções de verdades históricas em geral.

Esses dois eixos de análise se unem na medida em que é necessário levar em consideração, (1) de um lado, quais são as condições de produção da própria imagem fotográfica (que, não raro, coaduna as estratégias do poder às estratégias do ver e do representar) e, (2) de outro, quais as condições de produção da reapropriação dessas imagens produzidas (quando elas compõem o campo do conhecimento histórico e são inseridas em livros escolares, reinseridas em outros contextos discursivos). Foucault nos fornece arsenal teórico para discutirmos as duas questões.

Nesse aspecto, as ideias de Foucault são interessantes como motivadoras para a discussão sobre o uso de fotografias históricas como material didático, na medida em que fornecem instrumentos pedagógicos, que visam ampliar o domínio de conhecimentos dos alunos, justamente ao problematizar a construção dos saberes constituídos. 
OS MODOS DE VER, DE PODER E DE REPRESENTAR: A FOTOGRAFIA COMO DISPOSITIVO DISCIPLINAR E DISCURSIVO

Um primeiro ponto de discussão sobre as fotografias históricas como instrumento educacional sob a ótica das ideias foucaultianas diz respeito ao modo como as fotografias, historicamente, ligaram de maneira estratégica as formas de poder às formas de ver e de representar. Isso nos mostra como a própria produção fotográfica participa de determinadas condições de produção historicamente marcadas que devem, a todo momento, ser problematizadas junto aos alunos.

Entre o fim do século XVIII e início do século XIX, Foucault posiciona uma mudança radical na forma como o poder era exercido. $\mathrm{O}$ antigo suplício - espetáculo punitivo público que marcava um lugar de poder - é substituído gradativamente pelo poder disciplinar, de forma que "a punição vai-se tornando, pois, a parte mais velada do processo penal". Dentre as várias consequências desse processo, Foucault destaca que a pena "deixa o campo da percepção quase diária e entra no da consciência abstrata; sua eficácia é atribuída à sua fatalidade não à sua intensidade visível; a certeza de ser punido é que deve desviar o homem do crime e não mais o abominável teatro". E é "por essa razão, a justiça não mais assume publicamente a parte da violência que está ligada ao seu exercício. $O$ fato dela matar ou ferir já não é mais a glorificação de sua força, mas um elemento intrínseco a ela que ela é obrigada a tolerar e muito lhe custa ter que impor" (FOUCAULT, 1987, p.14).

O daguerreótipo, primeiro projeto viável de obtenção de imagens por meios fotossensíveis, surge para o público em um período historicamente próximo a essas mudanças judiciais apontadas por Foucault, em 1839, de forma que os dois projetos - o de representação de mundo e o de poder - se interligam desde os primórdios da fotografia. Posto que o poder disciplinar é caracterizado não mais por se apropriar dos corpos dos subordinados, mas sim, "tem como função maior adestrar; ou sem dúvida adestrar para retirar e se apropriar ainda mais e melhor" (FOUCAULT 1987, p. 143), a fotografia surge como uma das tecnologias de poder que ampliam o olhar hierárquico (a vigilância), a sanção normalizadora e o exame.

As câmeras fotográficas "definem a realidade de duas maneiras essenciais para o funcionamento de uma sociedade industrial avançada: como um espetáculo (para as massas) e como um objeto de vigilância (para os governantes)" (SONTAG, 2004, p. 195). De fato, a fotografia já serviu para os mais diversos propósitos de vigilância e comando. Tal como apontado por 
Sontag (2004, p. 32), é possível notar que, ao longo da história, "as fotos foram arroladas a serviço de importantes instituições de controle, em especial a família e a polícia, como objetos simbólicos e como fontes de informação". Não é por acaso que "na catalogação burocrática do mundo, muitos documentos importantes não são válidos a menos que tenham, colada a eles, uma foto comprobatória do rosto do cidadão".

O dispositivo disciplinar que a fotografia representa, contudo, sempre pareceu estar ligado a um tipo bastante específico de tecnologia de poder que combina as técnicas da hierarquia que vigia e da sanção que normaliza: o controle do dispositivo fotográfico constituiu-se, prioritariamente, no século XIX como"um controle normalizante, uma vigilância que permite qualificar, classificar e punir" (FOUCAULT, 1987, p. 153), em que as técnicas fotográficas estavam articuladas a um campo de saber que justificava uma estratégia de poder.

Tal como proposto por Foucault (1987, p. 154), tais tecnologias de poder fazem "a individualidade entrar em um campo documentário: seu resultado é um arquivo inteiro com detalhes e minúcias que se constitui ao nível dos corpos e dos dias". E, assim, "coloca os indivíduos num campo de vigilância situa-os igualmente numa rede de anotações escritas; compromete-os em toda uma quantidade de documentos que os captam e os fixam". Não é por acaso que "os procedimentos de exame são acompanhados imediatamente de um sistema de registro intenso e de acumulação documentária" que se referem a métodos de identificação, assimilação e descrição, bem como a organização de campos que permitam "classificar, formar categorias, estabelecer médias, fixar normas" (FOUCAULT, 1987, p. 155).

Desde os primeiros daguerreótipos, no século XIX, a imagem fotográfica surgiu com certa pretensão de catalogação do mundo. O gosto por paisagens e pessoas consideradas exóticas, típicas de certo modismo do século XIX, não serviam apenas como produto de consumo para as massas, mas, principalmente, como instrumentos de apoio para as administrações coloniais, na medida em que ofereciam um registro dos povos e das regiões que eram dominados. Nesse sentido, é possível destacar trabalhos fotográficos como o de Linnaeus Tripe (1822-1902), fotógrafo oficial de uma divisão do governo das Índias Orientais na Índia, "comprometendo-se a realizar fotografias de praticamente tudo o que estivesse sob seu domínio" (LORD, 2012, p. 92) ou de Désiré Charnay, em seu registro da península de Yacatán patrocinada pelo governo francês.

Mais do que um mero registro das localidades, empreendimentos como esse, com frequência buscavam fazer extensos catálogos da "arquitetura, 
das paisagens e das raças subordinadas à autoridade do governo" (LORD, 2012, p. 95) financiador em questão, de forma que essas imagens funcionavam como verdadeiros instrumentos de poder. Não é por acaso que a fotografia etnográfica foi praticada, em grande medida, por administradores coloniais, missionários, explorados e viajantes a serviço do Estado.

A ampliação da prática em meados do século XIX fez com que uma série de mecanismos de padronização fossem criados para a coleta das evidências fotográficas registradas.

O biólogo Thomas Henry Huxley propôs ao Ministério das Colônias a criação de um registro fotográfico das várias raças do Império Britânico, utilizando um sistema de avaliação que envolvia fotografias dos indivíduos em questão, nus, em poses específicas ao lado de uma escala, com a câmera posicionada a uma determinada distância. O método de John H. Lamprey, apresentado à Ethnological Society of London em 1869, empregava uma grade composta de linhas sustentadas por uma moldura grande, posicionada atrás do indivíduo. Segundo Lamprey, esse fundo facilitava a medição das características do corpo, possibilitando o registro das discrepâncias. Seu sistema foi amplamente adotado por antropólogos e cientistas durante a segunda metade do século XIX (SANDON, 2012, p. 141).

É com base nessa ordem de coisas que Alphonse Bertillon, chefe do Serviço de Identidade Judiciária da Polícia de Paris elabora a identificação antropométrica, um conjunto de procedimentos que combinavam a imagem fotográfica do indivíduo, às suas mensurações corporais (medida em número das partes fixas do corpo) e à descrição dos elementos fisionômicos, com as marcas corporais para instituir a identificação precisa de cada sujeito. A partir dos dados obtidos, era feito um catálogo de infratores com base nos detalhes de suas medidas corporais, de forma padronizada e devidamente registrada por meio de fotografias de perfil. Tal ação se coadunava com o fato de que a fotografia do corpo humano passava a desempenhar um papel importante na aplicação das leis, aliada à ideia de que certos indivíduos carregavam marcas corporais que os tornavam mais propensos ao crime e à degeneração moral.

Para Dubois (1993, p. 242), implícita ao sistema de Bertillon está a ideia de "ascender do corpo à alma, de aproximar, de ligar, de explicar uma pelo outro (todos os parricidas teriam testa em perspectiva e orelha de abano?). Em outras palavras, subjacente à bertillonagem, mas bem real, havia essa inferência dos corpos rumo às 'disposições do espírito"'. No bertillonismo há, para Dubois (1993, p. 242), um panoptismo da vigilância em que o desejo delirante de ver ("ver completamente, totalmente, medir, classificar, 
esquadrinhar") "abre para uma espécie de ficção. O tratado de Bertillon, nesse sentido, seria algo como o primeiro romance policial (o nascimento desse último lhe é, aliás, contemporâneo)".

As ataduras entre o biopoder e as imagens fotográficas também podem ser observadas no campo da medicina. Nesse sentido, as fotografias de Hugh Welch Diamond (1809-1886), que retratavam os seus pacientes psiquiátricos no sanatório Surrey County Asylum com o objetivo de catalogar em imagens os seus estados de espírito, durante a década de 1850, é apenas um exemplo que incorpora a obra fotográfica de outros médicos do período, como Guillaume-Benjamin-Amand Duchenne e Jean-Martin Charcot. Ao passo que, o primeiro tirava fotografias de seus pacientes durante as sessões de terapia de eletrochoque, o segundo catalogou, em imagens, mulheres que sofriam de histeria, bem como as expressões faciais humanas.

“Desse modo, a fotografia foi empregada para evidenciar sinais de diferenças, categorizadas em termos de raça, capacidade física e mental, doenças e anormalidades", com o objetivo de criar "registros compostos de tipos raciais e sociais para sustentar teorias de uma ordem social natural baseada em características hereditárias" (SANDON, 2012, p. 141).

Para Foucault (1999, p. 302) "dizer que o poder, no século XIX (...) incumbiu-se da vida, é dizer que ele conseguiu cobrir toda a superfície que se estende do orgânico ao biológico, do corpo à população, mediante o jogo duplo das tecnologias de disciplina, de uma parte, e das tecnologias de regulamentação, de outra". As articulações entre a fotografia e as instituições de poder mostram como o aparelho fotográfico atua como uma tecnologia de poder que articula, justamente, essas duas instâncias, através da catalogação e mensuração de mundo. Para Sontag (2004, p. 18), "desde seu início, a fotografia implicava a captura do maior número possível de temas. A pintura jamais teve um objetivo tão imperioso". E, assim, "a subsequente industrialização da tecnologia da câmera apenas cumpriu uma promessa inerente à fotografia, desde o seu início: democratizar todas as experiências ao traduzi-las em imagens".

A fotografia, portanto, articulou, desde o início do século XIX, uma coadunação de estratégias entre os modos de comando e os modos de representação ou, em outros termos, entre os modos de poder e os modos de ver a partir da máquina - que se constitui mesmo como um dispositivo disciplinar.

Tal é a problemática que envolve a apropriação de imagens históricas em um contexto escolar: elas próprias são frutos de uma articulação que liga as formas de poder às formas de ver, de maneira que elas devem ser utilizadas 
de maneira crítica. É preciso reconhecer quais foram as condições de produção dessas imagens.

Essa consideração das condições de produção, contudo, deve ser feita em, pelo menos, duas instâncias: a da própria produção da fotografia em si, como discutimos até aqui e, posteriormente, da sua inserção em um livro escolar. Tanto uma quanto outra carregam engendramentos específicos de poder e condições discursivas.

Esse segundo aspecto, leva em consideração quais são as condições que permitem que certas fotografias apareçam em determinados períodos históricos e outras não - bem como quais são as condições que fazem com que essas imagens sejam reapropriadas em um contexto de educação formal. Ou seja, para além de intencionalidades claras de articulação da fotografia para com o poder disciplinar, ela ainda o exerce a partir da forma como participa dos processos sociais de construção da realidade.

Sontag traz um exemplo interessante no que diz respeito a essa segunda problemática: ao comparar a cobertura fotográfica da Guerra do Vietnã e da Guerra da Coreia, conflito bastante apoiado pela opinião pública norte-americana, Sontag (2004, p. 28) questiona que "seria bom imaginar que o público americano não teria se mostrado tão unânime em seu apoio à Guerra da Coreia se tivesse deparado com provas fotográficas da devastação da Coreia, um ecocídio e um genocídio, em certos aspectos, ainda mais completo do que o infligido ao Vietnã uma década depois". Tal suposição, contudo, para a autora, é irrelevante, na medida em que "o público não viu tais fotos porque não havia, ideologicamente, espaço para elas".

Se "ninguém trouxe para sua terra natal fotos da vida cotidiana em Pionguiang, para mostrar que o inimigo tinha um rosto humano, a exemplo das fotos que Felix Greene e Marc Riboud trouxeram de Hanói" (SONTAG, 2004, p. 29), isso remete diretamente ao controle dos discursos circulantes: posto que a Guerra da Coreia era entendida pela opinião norte-americana como parte da luta entre o mundo livre e a União Soviética, "admitida essa caracterização, as fotos de crueldade do ilimitado poder de fogo americano não seriam pertinentes".

E assim, "Os americanos tiveram acesso a fotos do sofrimento dos vietnamitas (...) porque os jornalistas sentiam-se respaldados em seus esforços para obter tais fotos, visto que o evento fora definido por um número significativo de pessoas como uma feroz guerra colonialista" (SONTAG, 2004, p. 29). E é sob este aspecto que toda fotografia está sempre coadunada a um ambiente discursivo, de forma que não pode existir prova fotográfica sem que 
exista previamente uma apropriação discursiva, sujeita a controle de diversas ordens. "O que determina a possibilidade de ser moralmente afetado por fotos é a existência de uma consciência política apropriada" (SONTAG, 2004, p. 29).

Se tomada sob essa perspectiva, as fotografias históricas trazem sempre uma marca entre as formas do poder e as formas de representação da realidade.

Sobre esse aspecto, Foucault (1996, p. 22-23) sublinha que há sempre determinados desníveis entre os discursos, de forma que alguns deles se apresentam como meramente efêmeros, como relatos que "se dispersam e que desaparecem", como coisas que "'se dizem' ao correr dos dias e das relações, discursos que se esquecem no próprio ato que lhes deu origem". Há, no entanto, outro nível de discursos, estes mais fundamentais, que, ao contrário dos anteriores, dizem respeito a narrativas maiores que se repetem incessantemente e que fornecem o conteúdo dessas estórias mais efêmeras.

Trata-se de discursos que "estão na origem de certo número de novos atos de fala, atos que os retomam, os transformam ou falam deles, numa palavra, os discursos que, indefinidamente e para além da sua formulação, são ditos, ficam ditos, e estão ainda por dizer" (FOUCAULT, 1996, p. 22). Eles ajudam a semantizar a irrupção do novo, de forma que o que é dito é sempre acompanhado por estruturas de pensamento que já estão dadas. Visto sob este aspecto, "o novo não está naquilo que é dito, mas no acontecimento do seu retorno" (FOUCAULT, 1996, p. 26).

Cada fotografia, nesse sentido, não representa uma nova visão de mundo, mas sim, uma reiteração de um discurso, de forma que certas imagens são possíveis de serem tiradas em um determinado período histórico, ao passo que outras nunca emergem. Muito embora todo e qualquer objeto físico ou evento possa ser fotografado do ponto de vista técnico, Bourdieu (1998, p. 6) lembra-nos que "ainda assim, é verdade que, entre o número teoricamente infinito de fotografias que são tecnicamente possíveis, cada grupo escolhe uma quantidade finita e bem delimitada de assuntos, gêneros e composições" a serem fotografadas. E é nesse sentido que mesmo "a fotografia mais trivial expressa, a despeito das intenções explícitas do fotógrafo, o sistema de esquemas de percepção, pensamento e apreciações comuns ao grupo todo" (BOURDIEU, 1998, p.6). A partilha entre os acontecimentos que são fotografáveis e os que não são, portanto, carregam diferenciações e sistemas de privilégios inscritos nos grupos sociais, bem como certa posição ocupada pelo fotógrafo e seu objeto de representação.

Posta a relação que a imagem fotográfica coaduna entre os modos de ver e os modos de poder, cabe-nos perguntar agora, qual é a especificidade 
da fotografia histórica, quando ela é inserida nesse segundo contexto de produção, a dos livros escolares. Se as questões tratadas até esse momento remetem às condições de produção das fotografias, é interessante notar que elas entram em outra lógica de produção de saberes quando elas são consideradas como "fotos históricas" e passam a representar um instrumento de educação escolar.

Embora se por um lado "toda fotografia que apreciamos se refere ao passado" (KOSSOY, 2005, p. 42), na medida em que se trata de uma representação que não é mais do que o congelamento de um determinado instante decorrido, seja ele próximo ou distante, por outro, a fotografia também é constantemente reinserida em outros contextos que lhe fornecem outros circuitos narrativos - circuitos narrativos estes alheios ao contexto em que a própria fotografia foi tirada, criando outra cena simbólica para este ocorrido que lhe serviu de objeto. É essa reapropriação que torna a fotografia um objeto para o conhecimento histórico.

Nesse aspecto, a obra de Foucault também nos auxilia ao apontar os modos e processos específicos a partir dos quais os conhecimentos são constituídos. Para ele, a inteligibilidade dos conhecimentos da modernidade consiste em construir um discurso que fala sobre aquilo que o outro cala. Sobre isso, utilizaremos as asserções de Certeau, feitas com base nas ideias foucaultianas, sobre o modo como isso se aplica ao saber histórico.

\section{A HISTÓRIA COMO CONHECIMENTO SOBRE AQUILO QUE O OUTRO CALA: A FOTOGRAFIA E A FALA SOBRE O OUTRO}

Para Foucault, há uma característica que marca toda a constituição do saber e da inteligibilidade da cultura ocidental moderna: o fato de que os saberes se instauram em uma relação a um novo. Isso significa dizer que ela "desdobra uma problemática articulando um saber dizer a respeito daquilo que o outro cala" (CERTEAU, 2008, p. 15). Ao estudar o modo como a medicina se constitui como saber em O Nascimento da Clínica, Foucault mostra como "do século XVII ao XVIII, o que torna possível a convertibilidade do corpo visto em corpo sabido, ou da organização espacial do corpo em organização semântica de um vocabulário - e inversamente - é a transformação do corpo em extensão, em interioridade aberta como um livro" (CERTEAU, 2008, p. 15). Segundo as palavras do próprio Foucault (1977, p. 122), "o olhar clínico tem essa paradoxal propriedade de ouvir uma linguagem no momento em que percebe um espetáculo". 
Para Certeau, tal mecanismo não se resume apenas à medicina, mas torna-se uma marca da inteligibilidade moderna, sendo que tal mecanismo pode ser ampliado para outras práticas, como a história. Para ele, tanto uma medicina quanto uma historiografia modernas "nascem quase simultaneamente da clivagem entre um sujeito supostamente letrado, e um objeto supostamente escrito numa linguagem que não se conhece, mas que deve ser decodificada" (CERTEAU, 2008, p. 15).

Assim, da mesma forma que um médico transforma o corpo do paciente em um quadro legível (e, portanto, traduzível em linguagem), tal qual um código que pode ser decifrado, tal como um cadáver mudo exposto ao olhar que exige uma leitura especializada, a história opera o mesmo mecanismo com a memória. "Uma mutação análoga se produz quando a tradição, corpo vivido, se desdobra diante da curiosidade erudita em um corpo de textos". Assim, "estas duas heterologias (discursos sobre o outro) se constituíram em função da separação entre o saber que contém o discurso e o corpo mudo que o sustenta" (CERTEAU, 2008, p. 15).

E é por este motivo que o autor enfatiza a noção de que a historiografia nada mais faz do que fornecer túmulos escriturários para os mortos do passado, sendo que "a única pesquisa histórica do 'sentido' permanece, com efeito, a do Outro". O tratamento que ela dá a estes mortos, no entanto, é também bastante específico, na medida em que ela pretende, ao mesmo tempo, "compreender e esconder com o'sentido' a alteridade deste estranho ou, o que vem a ser a mesma coisa, acalmar os mortos que ainda frequentam o presente" (CERTEAU, 2008, p. 14).

A própria divisão da história em períodos - como ldade Média, Idade Moderna, etc. - já marca a diferença e efetiva a decisão de ser outro ou de, no mínimo, não ser mais o que havia sido até o momento. Este novo que emerge acaba por atestar aquilo que o precedeu como morto e receber um passado já marcado por rupturas anteriores. “Logo, o corte é o postulado da interpretação (que se constrói a partir de um presente) e seu objeto (as divisões organizam as representações a serem reinterpretadas)" (CERTEAU, 2008, p. 15).

Este outro, enquanto um objeto de saber mudo, não nos diz a respeito das origens ou do começo das coisas como forma de explicação do presente. Seu ponto de partida é sempre inverso: ele parte de determinações presentes e a atualidade é sempre o seu começo real. A historiografia, ao representar esse passado do qual se distingue, portanto, acaba por fazer uma triagem dos fatos de forma que devem ou não ser lembrados como forma de obter uma inteligibilidade para o presente. 
É por isso que o ato de escrever sobre o passado é"encontrar a morte que habita este lugar, manifestá-la por uma representação das relações do presente com o seu outro e combatê-la através do trabalho de dominar intelectualmente a articulação de um querer particular com forças atuais" (CERTEAU, 2008, p. 22).

Mais do que isso, no entanto, estão postas em sua operação, "as permanências ocultas" e "as rupturas instauradoras" que formam um amálgama, marcando uma relação ambígua com o passado que representa. Isso porque, se por um lado, a noção de um passado que já está acabado marca uma relação de identidade por diferenciação - a partir da suposição de uma ruptura que transforma uma tradição em um objeto do passado, em um outro - o corte se dá apenas por separação, de forma que não há uma eliminação efetiva.

Assim, "se, por um lado, a história tem como função exprimir a posição de uma geração com respeito às precedentes, dizendo: 'eu não sou isto', acrescenta sempre, a esta afirmativa, um complemento não menos perigoso, que faz uma sociedade confessar:'eu sou outra coisa além daquilo que quero e sou determinada por aquilo que denego" (CERTEAU, 2008, p. 56). É por isso que, a partir deste jogo entre dependência e autonomia, que o discurso histórico é ao mesmo tempo sua representação e seu reverso.

A história está, pois, em jogo nessas fronteiras que articulam uma sociedade com o seu passado e o ato de distinguir-se dele; nessas linhas que traçam a imagem de uma atualidade, demarcando-a de seu outro, mas que atenua ou modifica, continuamente, o retorno do 'passado'. Como na pintura de Miró, o traço que desenha diferenças através de contornos e que torna possível uma escrita (um discurso e uma 'historicização') é atravessado por um movimento que lhe é contrário. Ele é vibração de limites. A relação que organiza a história é uma relação mutável, na qual nenhum dos (dois) termos é o referente estável (CERTEAU, 2008, p. 48).

Certeau também aproxima o entendimento histórico com a relação que os povos antigos mantinham com os mitos. $E$ isso porque,

o relato dessa relação de exclusão e de atração, de dominação ou de comunicação com o outro (posto preenchido alternadamente por uma vizinhança ou por um futuro) permite à nossa sociedade contar-se, ela própria, graças à história. Ela funciona como o faziam ou fazem ainda, em civilizações estrangeiras, os relatos de lutas cosmogônicas, confrontando um presente a uma origem (CERTEAU, 2008, p. 55). 
A partir dos parâmetros postos por Certeau, contudo, o acesso a este outro se dá também de uma forma muito específica: ele se estabelece não a partir de uma relação de escuta, mas sim, a partir de uma relação de tradução, em uma verdadeira hermenêutica do outro.

A palavra do outro, neste contexto, é possuída pelo detentor do discurso, que se encarrega de dizer o que este outro poderia dizer se ele tivesse a palavra - dizendo, com isso, algo muito distinto. Para Certeau, essa relação de tradução não pode ser senão uma imposição de poder e, nestes termos, com a suposta intenção de retratar o outro, acaba-se falando de si mesmo. Tida como objeto exótico - e, como tal, objeto de censura - a fala do outro não serve senão para que seja efetuada uma volta a si mesmo, ou seja, serve como um mero pretexto para o estudo de si.

Ora, essa marca da inteligibilidade ocidental (na qual as instituições educacionais estão inseridas) se articula a partir de uma escritura que fala pelos outros ou, em outros termos, de uma relação de poder, a partir da qual o dono da palavra se instaura no lugar do outro, não para buscar o campo comum de entendimento, mas sim, para falar por ele, falar sobre o que ele supostamente cala. Desta forma, a escritura ocidental faz com que a palavra do outro seja entendida de forma diferente daquilo que este outro propriamente fala. $A$ relação é de uma tradução sem escuta.

Se tomados a partir desta perspectiva, é possível entrever que, embora as instituições educacionais articulem um espaço de visibilidade para as demandas públicas e sociais, esse espaço não deixa de ser problemático e ambivalente, na medida em que essa representação se processa a partir dessa relação de tradução. Essa equação está inserida em um espaço em que os acessos aos meios simbólicos são desiguais.

A partir desses pressupostos é possível perceber que as fotografias históricas estabelecem uma relação análoga enquanto objeto de conhecimento no contexto escolar. "É justamente em virtude da credibilidade que se atribui ao documento fotográfico - como espelho fiel dos fatos da história cotidiana - que (...) poder-se-á dar margem à criação de um passado que jamais existiu", para Kossoy (2005, p. 45), de forma que "a ficção pode então substituir o real, tendo o documento fotográfico como prova convincente, como constatação definitiva de legitimação de todo um ideário".

As fotografias históricas constituem-se justamente como esse objeto mudo que, ao ser exposto ao olhar, diz algo de acordo com um universo discursivo pré-determinado. 


\section{AS FOTOGRAFIAS HISTÓRICAS E SEUS USOS NA EDUCAÇÃO}

Ao comentar a visão nietzschiana sobre os usos da história, Michel Foucault retoma a ideia de uma representação sobre o passado que pode se apresentar tanto como remédio quanto como veneno. Isso porque ao mesmo tempo em que a história pode se apresentar como uma espécie de "verdade eterna", apoiando em si mesma a sua própria autoridade; ela também guarda a possibilidade de mostrar um olhar diferenciado sobre o mundo, um olhar que pode mostrar a variabilidade e o devir dos eventos.

Na leitura foucaultiana, a história pode se mostrar tanto como "uma verdade eterna, uma alma que não morre, uma consciência sempre idêntica a si mesma", como também mostrar a "acuidade de um olhar que distingue, reparte, dispersa, deixa operar as separações e as margens - uma espécie de olhar que dissocia e é capaz ele mesmo de se dissociar e apagar a unidade deste ser humano que supostamente o dirige soberanamente para seu passado" (FOUCAULT, 1979, p. 13).

Os sentidos históricos, assim, possuiriam três variações básicas que guardam em si a possibilidade tanto de um uso que favoreça a vida aquela que entende o desenrolar dos acontecimentos como um acaso da luta - quanto de uma apropriação que se apoie em misticismos - aquela que engendra uma ilusão de um "reencontrar" ou de um "reencontrar-nos".

O primeiro deles é o uso paródico ou burlesco. Na sua face negativa, ele se reveste de um oferecimento ao homem de algumas identidades sobressalentes, "aparentemente melhor individualizadas e mais reais do que a sua", que operam como uma espécie de disfarce não percebido. Assim, "alternadamente, se ofereceu à Revolução Francesa o modelo romano, ao romantismo a armadura de cavaleiro, à época wagneriana a espada do herói germânico" (FOUCAULT, 1979, p. 20). Em sua face positiva, a história aprende justamente a reconhecer a farsa e deixar claro que estas identidades oferecidas não se distinguem de uma mera paródia, de um "carnaval organizado".

Outro tipo de mau uso da história estaria posto nas buscas pelas raízes e continuidades do passado no presente. Ou seja, nestes lugares onde se cultiva "com uma mão delicada o que sempre existiu" e que conserva "para aqueles que virão, as condições sob as quais se nasceu", sem perceber que estas ações, sob a suposta máscara de um "eu", acabam por proibir toda a identidade. Também aqui, se quisermos reencontrar sua face curadora, se trata de reencontrar as farsas envoltas neste tipo 
de pensamento: trata-se de dissipar as raízes de nossa identidade. Para isso, é necessário um deslocamento de olhar, retirando as pretensões de demarcação do território supostamente único de onde todos nós teríamos vindo ("essa primeira pátria à qual os metafísicos prometem que nós retornaremos") em direção a busca pelas descontinuidades que atravessam o sujeito.

Por fim, um terceiro uso positivo que se pode retirar da história é o reconhecimento de que todo o conhecimento é necessariamente violento e que se "as religiões de outrora exigiam o sacrifício do corpo humano; o saber conclama hoje a experiências sobre nós mesmos, ao sacrifício do sujeito de conhecimento" (FOUCAULT, 1979, p. 22) - reconhecimento este para sempre escondido no uso venenoso da história.

A leitura foucaultiana de Nietzsche traz uma ideia interessante na medida em que aprofunda a noção de usos da história, incorporando mesmo, para além de uma mera planificação em termos de bom ou ruim, uma dupla tomada que sempre ronda o conceito - a de um uso da história como phamakon. Assim, ao mesmo tempo em que os usos da história podem dotar os seres de máscaras, também são capazes, se tomados a partir de um novo movimento, de se incumbirem da tarefa de removêlas. Trata-se de uma visada que toma mesmo como vastas as formas de recorrência ao passado.

Os usos das fotografias históricas em sala de aula não deixam de estar sujeitos a esta noção de pharmakon que os usos da história carregam.

É essa visão de história em Nietzsche que permeia toda a obra de Foucault. Weinrich (2001) comenta que esta apologia do esquecimento do jovem Nietzsche é posta sob determinadas limitações ao longo de seus escritos posteriores. Ao colocar a memória como a base de comunicação entre o devedor e o credor em relação às dívidas (culpas) em sua Genealogia da Moral, ele limita sua exigência por uma arte do esquecimento a partir de razões morais. "Portanto não se trata apenas daquilo que nós - com ou sem arte-podemos lembrar ou esquecer, mas também daquilo que - com ou sem arte - precisamos absolutamente lembrar, e talvez, ou talvez não, devemos esquecer" (WEINRICH, 2001, p. 183-185).

Ao se apropriar da visão nietzschiana que aloca simultaneamente a história como dano (afinal, "história demais mata o homem" e "somente o estado absolutamente não-histórico, anti-histórico, não gera apenas a ação injusta, mas todo ato de justiça") e como necessidade ("em termos de imitação da grandeza, de veneração pelas tradições passadas e no 
exercício crítico do julgamento"), Ricoeur coloca que, nessa perspectiva, é na invocação à juventude que "surge in fine o termo insistente da doença histórica, o qual por sua vez traz o tema do remédio do qual não se sabe afinal se é também veneno, em razão de sua aliança secreta com a justiça que condena" (RICOEUR, 2007, p. 308).

\section{HISTORICAL PHOTOGRAPHS AS DISCIPLINARY DEVICES: POWER OVER THE SPEECH OF OTHERS IN THE SCHOOL CONTEXT}

AвSTRACT: This article refers to Michel Foucault's ideas in order to analyze the appropriation of historical images in school textbooks. First, we discuss the production conditions of the photographic image itself, which, not infrequently, unites strategies of power with those of seeing and depicturing. Then, we address the production conditions of the reappropriation of these produced images when they are reinserted in books and in other discursive contexts. In this respect, Foucault's ideas provide pedagogical tools which are intended to increase students' knowledge domain by problematizing the construction of constituted knowledge.

KeYwords: Foucault. Photography. History. Power. Discursive strategies.

\section{LAS FOTOGRAFÍAS HISTÓRICAS COMO DISPOSITIVOS DISCIPLINARIOS: \\ EL PODER SOBRE EL DISCURSO DEL OTRO EN UN CONTEXTO ESCOLAR}

Resumen: Este artículo nos remitirá a las ideas de Michel Foucault para analizar la apropiación de las imágenes históricas en los libros didácticos escolares. Primeramente, discutiremos cuales son las condiciones de producción de la propia imagen fotográfica, la cual, no raramente, unen las estrategias del poder a las estrategias del ver y del representar. Después, nos remitiremos a las condiciones de producción de la reapropiación de esas imágenes producidas cuando ellas son reinsertadas en los libros y en otros contextos discursivos. En este sentido, las ideas de Foucault nos proporcionan herramientas pedagógicas destinadas a ampliar el dominio de los conocimientos de los alumnos precisamente cuando se problematiza la construcción del conocimiento constituido.

Palabras Claves: Foucault. Fotografía. Historia. Poder. Estrategias discursivas. 


\section{REFERÊNCIAS}

BELMIRO, C. A. A imagem e suas formas de visualidade nos livros didáticos de português. Educação e Sociedade, ano XXI, n. 72, p. 11-31, ago. 2000.

CERTEAU, M. de. A Escrita da História. Rio de Janeiro: Forense Universitária, 2008.

DUBOIS, P. O Ato Fotográfico. Campinas: Papirus, 1993.

FARIA, A. L. Ideologia do Livro Didático. São Paulo: Cortez, 1984.

FOUCAULT, M. O Nascimento da Clínica. Rio de Janeiro: Forense Universitária, 1977. . Microfísica do Poder. Rio de Janeiro: Graal, 1979.

. Vigiar e Punir: o nascimento da prisão. Petrópolis: Vozes, 1987. . A Ordem do Discurso. São Paulo: Loyola, 1996.

. Em Defesa da Sociedade. São Paulo: Martins Fontes, 1999.

LORD, Russell. Retratando o mundo. In: HACKING, J. Tudo sobre Fotografia. Rio de Janeiro: Sextante, 2012. p. 92-99.

RICOEUR, P. A Memória, a História, o Esquecimento. Campinas: Editora da Unicamp, 2007.

SANDON, E. Fotografia e ciência. In: HACKING, J. Tudo sobre Fotografia. Rio de Janeiro: Sextante, 2012. p. 140-146.

DA SILVA, H. C.; et al. Cautela ao usar imagens em aulas de ciências. Ciência e Educação, v. 12, n. 2, p. 219-233, 2006.

SONTAG, S. Sobre Fotografia. São Paulo: Companhia das Letras, 2004.

WEINRICH, H. Lete: arte e crítica do esquecimento. Rio de Janeiro: Civilização Brasileira, 2001.

Eliza Bachega Casadel é doutora em Ciências da Comunicação pela Escola de Comunicações e Artes da Universidade de São Paulo (ECA-USP) e professora da Faculdade de Arquitetura, Artes e Comunicação da Universidade Estadual Paulista Júlio de Mesquita Filho (FAAC-UNESP). Mestre em Ciências da Comunicação e bacharel em jornalismo pela ECA-USP.

E-mail: elizacasadei@yahoo.com.br 